\title{
Evolution of Ascariasis in Humans and Pigs: a Multi-disciplinary Approach
}

\author{
Odile Loreille/ ${ }^{+}$, Françoise Bouchet ${ }^{*}$
}

\author{
Institute of Evolutionary and Ecological Sciences, University of Leiden, PO Box 9516, 2300 RA, Leiden, the Netherlands \\ *Laboratoire de Paléoparasitologie CNRS ESA 8045, Université de Reims, Reims, France
}

The nematode parasite Ascaris lumbricoides infects the digestive tracts of over 1.4 billion people worldwide, and its sister species, Ascaris suum, has infected a countless number of domesticated and feral pigs. It is generally thought that the putative ancestor to these worms infected either humans or pigs, but with the advent of domestication, they had ample opportunity to jump to a new host and subsequently specialize and evolve into a new species. While nuclear DNA markers decisively separate the two populations, mitochondrial sequences reveal that three major haplotypes are found in A. suum and in A. lumbricoides, indicating either occasional hybridization, causing introgression of gene trees, or retention of polymorphism dating back to the original ancestral species. This article provides an illustration of the combined contribution of parasitology, archaeoparasitology, genetics and paleogenetics to the history of ascariasis. We specifically investigate the molecular history of ascariasis in humans by sequencing DNA from the eggs of Ascaris found among ancient archeological remains. The findings of this paleogenetic survey will explain whether the three mitochondrial haplotypes result from recent hybridization and introgression, due to intensive human-pig interaction, or whether their co-occurrence predates pig husbandry, perhaps dating back to the common ancestor. We hope to show how human-pig interaction has shaped the recent evolutionary history of this disease, perhaps revealing the identity of the ancestral host.

Key words: Ascaris - Ancient DNA - archaeoparasitology - Ascaris suum - Ascaris lumbricoides

Ascariasis is a disease caused by the nematode Ascaris lumbricoides and is one of the most widespread parasitic infections in humans, affecting over 1,47 billion people worldwide, particularly in tropical and subtropical areas (Chan et al. 1994, Crompton 1999). The life cycle is direct, which means that no intermediate hosts are involved. These worms are mainly present in communities where poverty prevails, where there is a lack of safe drinking water and where sanitation is poor, but $A$. lumbricoides is also present in the USA, where about four million people are infected (Valentine et al. 2001) as well as in Europe (Muller 1975, Denham 1984, Nikolic et al. 1998, Tomaso et al. 2001). In Austria for example, ascariasis is the third most prevalent helminthic infestation (Tomaso et al. 2001).

A closely related sister species of $A$. lumbricoides infects pigs. Goeze described it for the first time in 1782 and called it A. suum. The swine worm is responsible for significant economic losses: it reduces production efficiency and causes organ condemnations at slaughter due to pathology produced by parasite larval stages.

For many years, parasitologists thought that the life cycle of $A$. suum was identical to that of the human parasite, A. lumbricoides (Fig. 1). However, Murrell et al. (1997) recently demonstrated that $A$. suum $\mathrm{L}_{2}$ larvae in the pig host have a stronger predilection for the caecum and colon intestinal mucosa than for the small intestine. This finding raises important questions as to whether $A$. suum

${ }^{+}$Corresponding author. E-mail: jperk @ chello.nl Received 26 August 2002

Accepted 25 November 2002 and $A$. lumbricoides share similar migratory and development patterns in their hosts. In fact, there has been much speculation over the years as to whether or not $A$. lumbricoides Linnaeus, 1758 from humans and $A$. suum Goeze, 1782 from pigs were originally the same parasite that evolved into two separate species. Today, they continue to be discussed as if they were separate species, although it is very difficult to distinguish them. Generally, the adults can be identified based on morphological characters but there is still no convenient method for discriminating between an egg of $A$. lumbricoides and A. suum. Numerous studies have attempted to clarify their status using morphological (Sprent 1952, Ansel \& Thibaut 1973), immunological (Kurimoto 1974, Nadler 1987), karyotypic (He et al. 1986), and biochemical approaches (Mikulikova 1976, Paggi et al. 1985), but results were difficult to interpret because most worms were obtained from different locations, rendering the differentiation between geographic and host-related variation impossible.

Should A. suum and A. lumbricoides be regarded as two different species as it is currently the case? Today there are six different species concepts in use, all with strengths and weaknesses, and this makes it very difficult, if not impossible, to settle the status of A. suum and $A$. lumbricoides once and for all. In order to know if the two worms are the same or separate species in BSC biological species concept (Dobzhansky 1937) - it is important to determine whether worms from one sex retrieved from pigs and worms from the other sex retrieved from humans can mate and produce viable offspring. The results of this hybridization experiment would require the production of eggs which give rise to successive generations of fertile worms thereby establishing in biological terms that $A$. lumbricoides and A. suum are the same spe- 


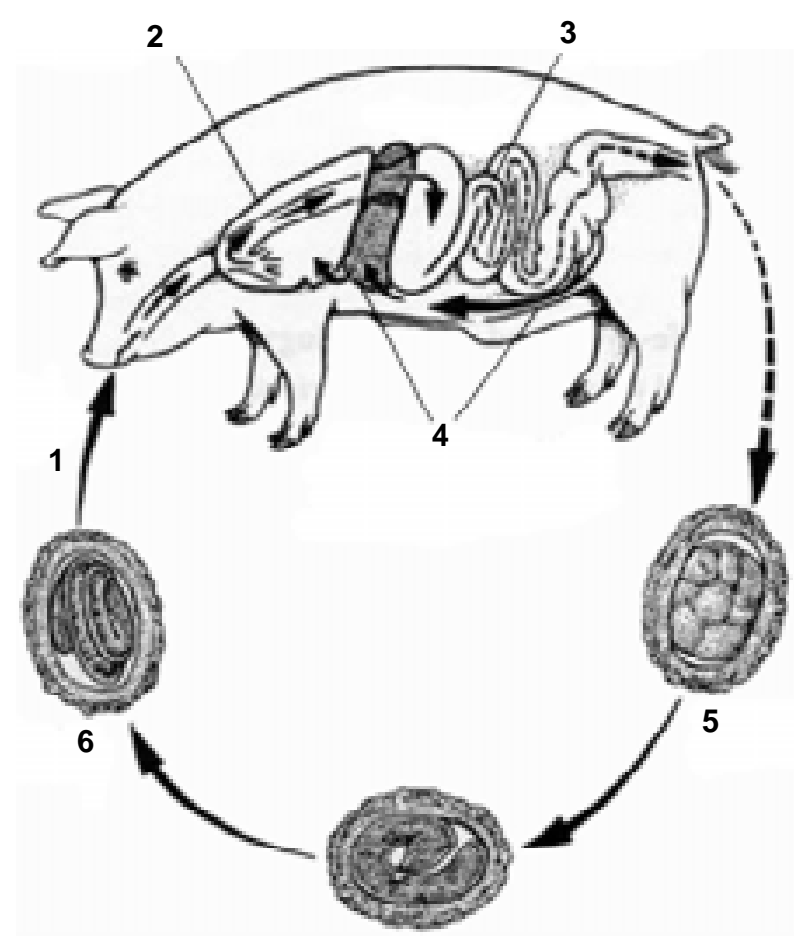

Fig 1: Ascaris suum life cycle, (from Jungersen 1998). 1: ingestion of infective eggs; 2 : the larvae migrate up the bronchi and are swallowed; 3: the larvae establish in the small intestine and become patent at week $6-8 ; 4$ : hatched larvae penetrate the large intestinal wall and migrate via the liver to the lungs; 5 : unembryonated egg in faeces; 6: infective egg with $\mathrm{L}_{2}$ larva.

cies (Crompton 2001). Although this area of research is active, so far no significant result has been obtained (Jungersen pers. commun.).

For the past ten years, several disciplines, offering different perspectives for elucidating the history of the Ascaris, have extensively progressed. We will now review the inferences from parasitology, archeoparasitology, genetics and paleogenetics since it became obvious that a interdisciplinary approach will obviously be the best way to understand the history of Ascaris.

\section{INFERENCES FROM PARASITOLOGY}

Regarding the fidelity of the parasite to its host, it is crucial to determine if the two Ascaris have a single transmission cycle in which humans and pigs are alternative hosts or if they have two sympatric life cycles, with one using humans as a host and the other the pigs.

In his thesis, Jungersen (1998) reports an experiment performed by Buckley (1931), who deliberately ingested a piece of bread contaminated with twenty larvae collected from the lung of a pig recently infected with a massive dose of A. suum eggs. Simultaneously, Buckley infected a green monkey and two pigs with a much bigger amount of larvae. Three months after the transfer, Buckley and the green monkey still had not shown any clear sign of infection whereas both pigs were found to harbor large quantities of adult worms. However, new cross infection experiments have demonstrated that humans can actually be infected with eggs derived from pigs (Takata 1951,
Crewe \& Smith 1971, Lord \& Bullock 1982) and that pigs may be infected with parasite ova from humans (Galvin 1968). Although these experiments are very important, until recently they were not considered very reliable because the immune mechanism of the pigs was distorting the results of the experiments (in some circumstances pigs have the ability to self-cure). The other problem is that the large doses of ova used in these experimental infections may be unrepresentative of the natural transmission of Ascaris. Fortunately, in 1996, a new and promising method for transferring adult Ascaris was described by Jungersen and the outcome of future experiments in this area are awaited with great interest (Jungersen et al. 1996, 1997).

In natural conditions, Anderson (1995) showed that in North America, a pig ascarid infection could occasionally be spread to humans and that it mostly occurred when infective eggs found in the soil and manure were ingested. Infection is more likely if pig feces are used as fertilizer in gardens and crops become contaminated with ascarid eggs. However, these natural cross-infection events seem to be quite limited. In fact, Anderson showed in another study that, in Guatemalan villages, parasites infecting humans and parasites infecting pigs were reproductively isolated (Anderson et al. 1993, Anderson \& Jaenike 1997). By studying the mitochondrial diversity from several populations of pig and human Ascaris, he concluded that there was little or no gene flow between the two populations of worms and he ruled out the hypothesis stating that Ascaris had a single transmission cycle in which humans and pigs are alternative hosts (Anderson 2001). At least two hypotheses could explain the discrepancy found between the North American and the Guatemalan data: either cross infections do occur in Guatemala but since they are rare, they have been detected with the molecular markers used by Anderson, or there is a difference in host immunity between populations.

With an estimated 8,000 to 100,000 children dying from ascariasis every year (Editorial 1989), it is crucial for the World Health Organization to know more about those worms to develop and promote efficient drugs and control strategies. If it turns out that pig Ascaris can infect humans (and vice versa), there seems to be little point in spending resources on anthelminthic drugs because reinfection would seem inevitable, particularly in farms where human populations use contaminated pig manure. It is also important to determine if species other than pigs or humans can serve as reservoir hosts. A. lumbricoides might have been identified in squirrels (Rausch \& Tiner 1948), but the authors doubted that the very large worms could mature in such small animals. Further evidence suggests that A. lumbricoides can also infect bears (Juniper 1978) and primates (Stuart et al. 1990), and that accidentally A. suum could infect cattle and sheep.

\section{INFERENCES FROM ARCHEOPARASITOLOGY}

Archeoparasitology appeared as a new branch of parasitology in the beginning of the 20th century, when a new technique to rehydrate desiccated tissues allowed the finding of Schistosoma haematobium eggs in infected kidneys of 3,200 year-old Egyptian mummies (Ruffer 1910). The other main sources for parasite remains are the co- 
prolites that are desiccated or mineralized faecal material found at archaeological excavations. Today human-parasite coevolutionary studies based on archeoparasitological findings are widely performed, showing the antiquity of parasite-host relationships and tracing the origin and dispersion of the infection to prehistoric times (Araujo \& Ferreira 2000).

Parasitologists have reported that Ascaris eggs are difficult to exterminate. They remain viable in soil for as long as 15 years and are almost as widespread in the environment as bacteria (O'Lorcain \& Holland 2000). Archeoparasitologists have also reported that fossilized Ascaris eggs were common in archaeological sites. Unlike bacterial or viral pathogens, nematodes produce eggs that are easy to detect under a microscope and which can confirm the presence of an infectious disease even if the remains of the host are poorly preserved or absent. The relative abundance of eggs on archaeological sites can be attributed to their thick shell which seems to improve their preservation through time (Fig. 2). Furthermore, the fact that adult females Ascaris females lay on average 200,000 eggs per day increases significantly the chances of recovering fossilized nematodes.

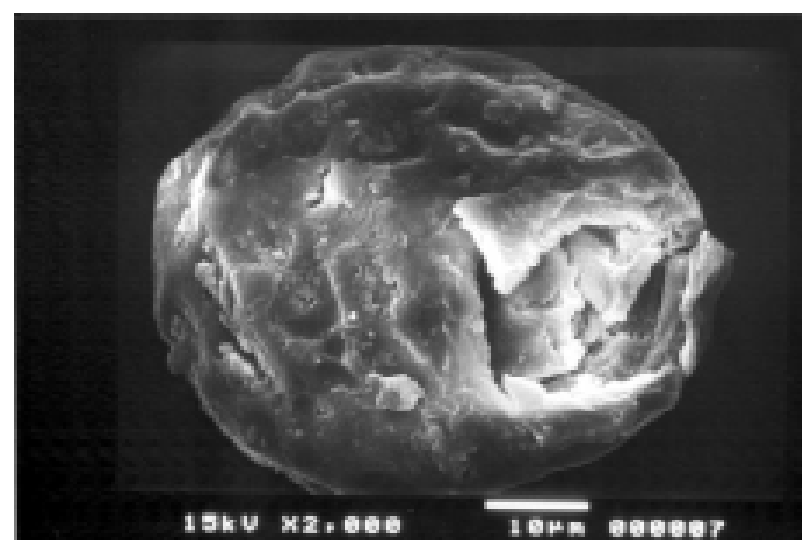

Fig 2: ancient egg of Ascaris sp. with a broken shell after passage of ultrasonic wave $\left(20 \mathrm{~min}\right.$ at $\left.60^{\circ} \mathrm{C}\right)$.

The presence of Ascaris in Europe, Africa, and even in the New World indicates that Ascaris represents a very successful human nematode. It evolved mechanisms that promoted infection in diffuse populations living in extreme and cold environments. All these findings suggest that humans and Ascaris have a very long history. Ancient Greeks and Romans were familiar with Ascarids, and intestinal complaints were mentioned in the Ebers Papyrus and in writings of Chinese medicine.

Although A. suum and A. lumbricoides eggs cannot be morphologically distinguished, archeoparasitology might be a very promising discipline for the identification of the ancestral hosts of Ascaris. Were the first hosts humans or pigs? The actual hypothesis states that $A$. lumbricoides evolved from a pig Ascaris, presumably A. suum, following the domestication of pigs by humans in the Neolithic or Paleolithic (Kliks 1983). Today wild pigs are infected by A. suum, so it is possible that ancient populations of wild pigs were infected by Ascaris before becoming domesticated. If this hypothesis is true, A. suum should be the only roundworm present in deposits preceding pig domestication. To investigate the interactions between Ascaris, pigs and humans, it is thus crucial to use a dynamic multifaceted approach involving the history of our domestic pigs.

Ancestors of today's swine date back to the Miocene. The hunting of wild pigs by early humans was often depicted in Western European cave and rock paintings as early as 25,000 years ago. Domestic pigs all descend from a single species, the Eurasian wild boar, Sus scrofa (Epstein \& Mason 1984). Their domestication probably occurred over 9,000 years ago in the Middle East and eastern Mediterranean although an alternative view places the beginning of swine domestication in Southeast Asia. Sauer suggested that the pig diffused from there northward to China (Sauer 1952). Today most archaeologists favor the hypothesis that two separate pig domestications occurred at different times and places in the Old World. Domesticated pigs then progressively spread across Asia, Europe and Africa.

If wild pigs are the ancestral hosts of Ascaris and if the host shift really occurred during pig domestication, then archaeoparasitologists should not find fossilized $A$. lumbricoides in deposits preceding the arrival of domesticated pigs.

The oldest Ascaris eggs recovered so far were collected in the 30,000 year-old upper-Paleolithic site of Arcy-sur-Cure, Yonne, France (Bouchet et al. 1996). This cave is characterized by several wall paintings and by the large amount of Ursus spelaeus remains. No pig remains were identified. The authors stated that even if wild pigs had been present close to the site, they would not have gone so far inside the cave and thus concluded that the Ascaris samples were most probably A. lumbricoides eggs. If $A$. lumbricoides were present in France before the arrival of domesticated pigs, it seems unlikely that domesticated pigs infected humans with Ascaris. In contrast, we can suggest that hominids were in fact the ancestral hosts and that they later infected their domesticated pigs. Finally, since pigs ingest human feces (and not vice versa) the hypothesis stating that humans were the ancestral hosts is very plausible.

To check this hypothesis, we will analyze more fossilized Ascaris eggs. Although, on a morphological basis only, it is impossible to determine if a fossilized Ascaris egg belongs to A. suum or to A. lumbricoides, sometimes, like in Arcy-sur-Cure, circumstances around the discovery can help. For example, here we report evidence of the presence of ascariasis in past populations of Nubia, in Africa. The Nubians inhabited the area along the Nile from the first cataract south to the sixth cataract. Today this land lies inside of Sudan. It was known as the Kingdom of Kush and it even ruled over Egypt for a while. Saï, one of the largest islands in the Nubian Nile, includes a large number of archaeological sites ranging from Palaeolithic to more recent times (Geus 1995). Because of the region's very arid climate, many naturally mummified remains have been found on the island. Very well preserved Ascaris 
egg samples were recovered inside at least two human mummies, one dated between 300-1500 AD, and the other dated between 2050-1750 BC. The context of the finding makes it almost certain that the samples belong to the $A$. lumbricoides species.

In order to know more about the history and migration of the two worms, it is not only important to determine the ancestral host but also crucial to learn more about cross infections. One can suppose that if cross infection can occur today, they were probably very rare when humans and pigs had little or no contacts. Thus, it would be interesting to search for fossilized Ascaris in areas where pigs have been introduced recently. For example, one interesting location to search for samples of ancient $A$. lumbricoides samples is the New World.

For many years scientists thought that the prehistoric New World was free of parasitic disease. This belief was then discredited in the late 1970s by archeoparasitologists who showed that parasites maintained infections as humans migrated through the Bering Land Bridge into the New World. Patrucco reported evidence of infertile eggs of Ascaris in coprolites collected in the site of Los Gavilanes, Peru, and dated 2277 BC (Patrucco et al. 1983). Reinhard et al. (1987) identified Ascaris in coprolites from five archaeological sites from the Colorado Plateau of Arizona and Faulkner encountered the A. lumbricoides in eight samples of desiccated human faeces from Big Bone Cave, Tennessee (Faulkner et al. 1989). Associated $C^{14}$ dated material suggested an age of $2177 \pm 145 \mathrm{BC}$. Ascaris eggs were also identified in the abdominal cavity of a child found at Zero Point, Alaska, and dated $840 \pm 40 \mathrm{BP}$ (Bouchet et al. 2001). In this context, the authors also concluded that the parasites were undoubtedly $A$. lumbricoides.

The oldest human remains recovered so far in the New World come from the site of Monte Verde and are most likely descendants of people who reached North America by crossing the Bering land bridge from Asia at least 12,000 years ago, perhaps more (Greenberg et al. 1986). In contrast, the introduction of swine in the New World occurred recently, during Christopher Columbus' second voyage in 1493 (Gade 2000). From an original stock of eight, pigs multiplied on the Caribbean island of Hispaniola. Later, 13 pigs arrived in what is now the United States from Cuba with Hernando de Soto's expedition (1539-1542) through the Atlantic Coast of Florida. The explorer offered live pigs to the Indians, and when he died in 1542 pigs then amounted to over 700 , not including those that had wandered away from the constraints of domestication to reach the vast American wilderness. The fossilized Ascaris samples identified in the New World (Patrucco et al. 1983, Reinhard et al. 1987, Faulkner et al. 1989, Bouchet et al. 2001) are certainly the descendants of worms brought by colonists. Unless these people were accidentally infected by $A$. suum, it is very probable that $A$. lumbricoides entered the New World long before A. suum.

\section{INFERENCES FROM GENETICS}

Genetic typing of modern pathogenic agents has gone through impressive developments in the past 10 years, thanks to advancements in molecular biology. Sequence data is being used to infer ancestral relationships among pathogens and to help address relevant questions about their origins. The evolution of nematode mtDNA is generally quite unusual: it is highly $\mathrm{A}+\mathrm{T}$ rich, prone to recombination and gene rearrangement, and evolves faster than mitochondrial DNA (mtDNA) of other taxa (Blouin et al. 1998). Although the complete mtDNA genome of A. suum has been sequenced, there is still little data about the genetic diversity of both Ascaris species. Several comparative studies are needed, using similar sampling designs and the same DNA markers, including nuclear loci and further work with mtDNA.

In studies involving Ascaris from several localities, differences in DNA patterns have been used to differentiate the two parasites. Anderson et al. (1993) analyzed mitochondrial markers to investigate the transmission of Ascaris from two sites in Guatemala. The sequences they obtained generally fell into two distinct clusters that are 3-4\% divergent: cluster A predominantly identified in parasites from pigs, and cluster B in parasites from humans. The authors concluded that Ascaris from pigs and humans have two distinct transmission cycles with little or no gene flow between populations. However, surprisingly, they noticed that some mitochondrial haplotypes were present in worms obtained from both host-species. The authors presented the following hypotheses to explain their data: (1) the cross-infection hypothesis: A. suum and A. lumbricoides represent two reproductively isolated parasite populations specializing on two different hosts and defined accurately by both nuclear and mtDNA, but they show incomplete host fidelity, or (2) the evolutionary hypotheses: either low levels of gene flow led to introgression of genes between host-associated parasite populations (introgression), either the separation between A. suum and A. lumbricoides is too recent for alleles to have reached a state of reciprocal monophyly (retention of ancestral polymorphism).

To verify these hypotheses, Anderson and Jaenike (1997) compared patterns of variation in the mitochondrial and in the nuclear genome of Ascaris using the parasites they had studied and 42 additional parasites from worldwide locations. A concordance between nuclear and mitochondrial markers would support the cross-infection hypothesis, while a lack of such support would favor the alternative hypotheses. The results obtained with multiple nuclear markers were incongruent with that revealed by mtDNA. The authors concluded that cross-infection is extremely rare and/or very short duration. In this new study three major clades (A, B, C), which differ in sequence by up to $5.8 \%$, were identified (Fig. 3). Despite lacking a solid calibration for the Ascaris molecular clock, the authors estimated divergence among the three major clades, and cautiously concluded that their data favored retention of ancestral polymorphisms over introgressive hybridization (Fig. 4). Although they also concluded that their data was favoring a single host shift, they were unable to determine who the ancestral host of Ascaris was. One would expect that parasites infecting the ancestral host will be more genetically diverse than those that recently colonized a new host species, but among the seven polymorphic nuclear loci examined by the authors, 22 al- 
leles were found in worms from pigs and 20 in worms from humans. This slightly greater genetic diversity in worms from pigs could suggest that pigs served as the ancestral host and would thus contradict the fossil record. However, the authors admit that the analysis of more loci is necessary to better resolve the relationships between the two worms and to determine the region in which the host shift occurred.

\section{INFERENCES FROM PALEOGENETICS}

Molecular biologists use molecule patterns to infer relationships between organisms. Unfortunately, the increasing interconnections among populations often make data difficult to interpret. For example, in the case of $A s$ caris, it is possible that the host shift occurred during the Neolithic because pigs started to be domesticated by human populations with a size and a density important enough to maintain sustained epidemics. Then, during the next thousand years, due to the increasing mobility of humans, parasites previously confined to specific geographical locations were able to spread widely.

In the 1980s, it was shown that molecules of DNA could be preserved in ancient soft tissues (Higuchi et al. 1984, Pääbo 1985) and in bone material (Horai et al. 1989, Hagelberg et al. 1989). Today, by using the polymerase chain reaction (PCR), it is possible to detect and amplify the rare DNA fragments that have been scarcely preserved in fossils, including DNA from the pathogens they hosted. Using this approach, the spectrum of infectious diseases that can be studied in ancient samples has been considerably enlarged and it is now possible to get a precise diagnostic even before any clear sign of infection, and to distinguish between pathologies and ante mortem lesions. Thus, molecular paleopathology constitutes a powerful tool to the discernment of infectious diseases in the past. For example, Trypanosoma cruzi DNA was recovered using PCR in Chilean human mummified remains (Guhl et al. 1999, Ferreira et al. 2000). Those two studies enabled the identification of Chagas disease in ancient bodies in the absence of recognizable anatomic pathological changes.

However, the retrieval of ancient DNA sequences is far from routine and since nobody had ever successfully amplified ancient DNA from helminthes before, we started our investigation with a preliminary study to determine whether we could extract and amplify DNA from embryos preserved in ancient parasite eggs (Loreille et al. 2001). The Middle-Age site of "Place d'Armes" in Namur (Belgium) was selected because of its excellent taphonomic conditions (permanently humid and anaerobic). Several coprolites were recovered from a 14th Century latrine that also contained abundant archaeological material. The coprolites revealed a very high concentration of parasite eggs, some of which still had fossilized embryos inside. Based on their morphology, we identified the samples as Ascaris sp. eggs, although it could not be determined if they belonged to A. suum or to A. lumbricoides. We successfully extracted DNA from 104 fossilized eggs. A 176 base-pair fragment of nuclear 18S ribosomal RNA and a 98 base-pair fragment of the mitochondrial gene cytochrome $\mathrm{b}$ were amplified without contamination. These sequences confirmed the morphological identification to Ascaris and proved that our sequencing techniques could work on ancient samples. Unfortunately it was difficult from our results to identify the species of Ascaris that was present in the archaeological site. Currently we are trying to amplify more loci in order to determine if those eggs belong to $A$. suum or to A. lumbricoides. In addition

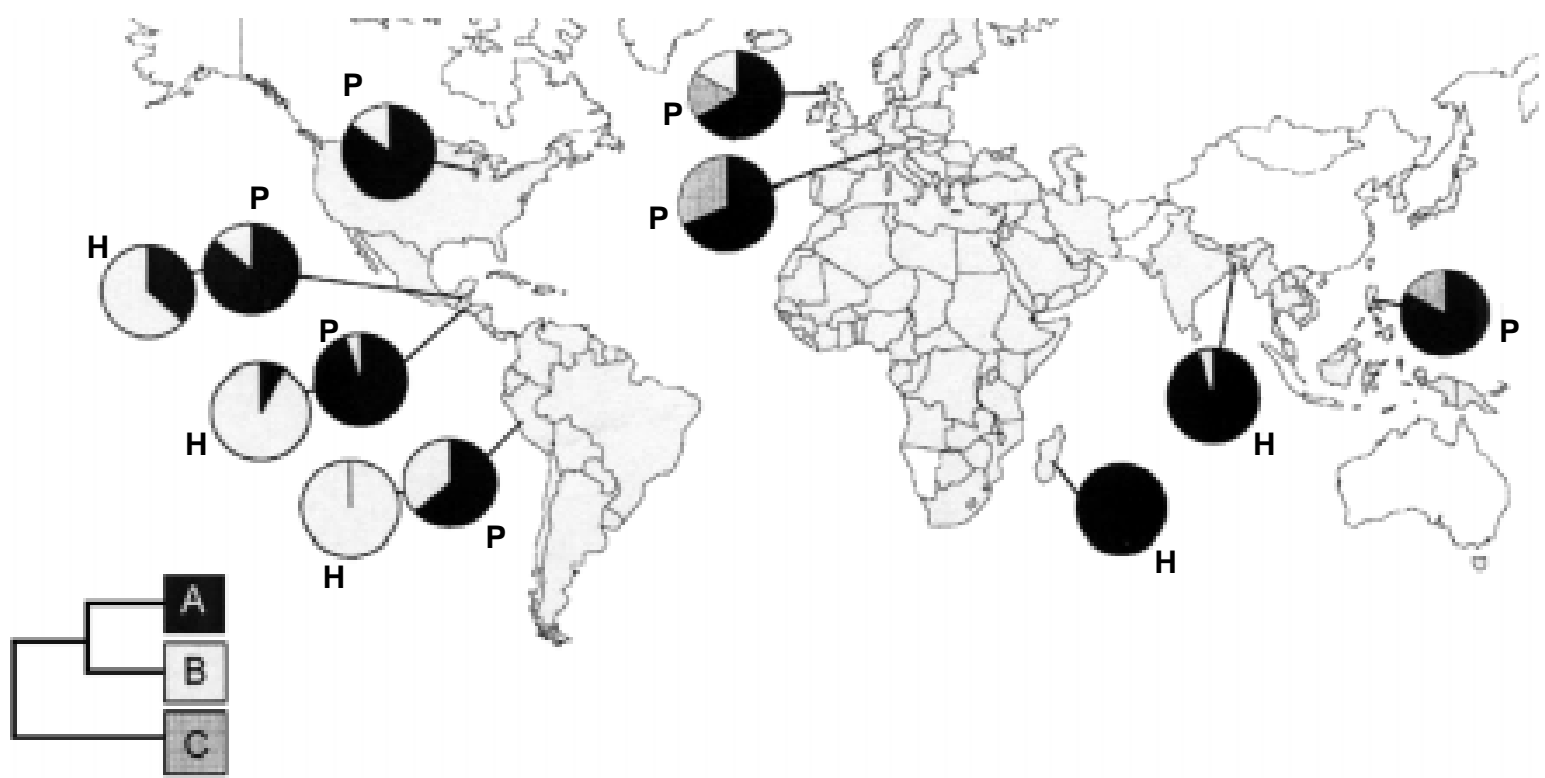

Fig 3: global distribution of the three major clades of mitochondria DNA (mtDNA) in Ascaris populations from world-wide locations (from Anderson \& Jaenike 1997). Each pie chart represents a single parasite population: those marked with a $\mathrm{P}$ were obtained from pigs, while those marked $\mathrm{H}$ were from humans. Where parasites have been obtained from both host species from the same location (Guatemala and Peru) two pie charts are connected with a line. The insert (bottom left) shows the phylogenetic relationships between the three mtDNA clades. Sample sizes for parasites from pigs were: Guatemala, 38+36; Peru, 11; Switzerland, 19; Scotland, 12 ; USA, 20 ; Philippines, 18. Sample sizes for parasites from humans were: Guatemala, 39+42; Peru, 14; Madagascar, 15; and Bangladesh, 18. 
(1)

(2)
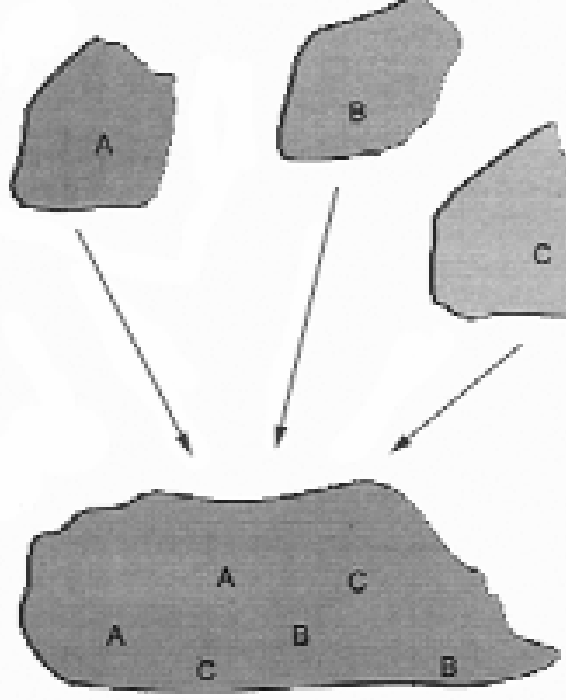

(3)

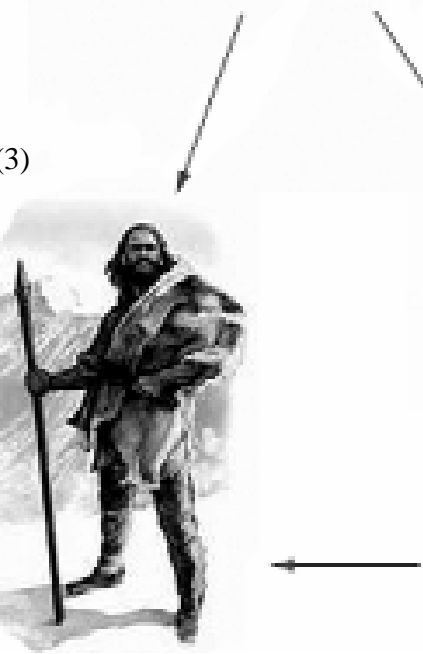

Fig 4: a possible historical scenario for the peculiar distribution of mitochondria DNA (mtDNA) haplotypes in Ascaris, based on retained ancestral polymorphisms (from Anderson 2001). A threestage process is envisaged: (1) geographical isolation of ancestral Ascaris populations leading to the evolution of divergent mtDNA haplotypes (including clusters A, B and C observed today); (2) 102,000 years ago-mixing of Ascaris populations bearing divergent mtDNA; and (3) host specialization leading to current situation in which $\mathrm{A}, \mathrm{B}$ and $\mathrm{C}$ clusters of mtDNA are found in populations of parasites infecting both humans and pigs. This scenario is based on global mixing of a previously isolated parasite population, as a result of domestication and recent human migrations.

we plan to amplify and sequence ancient DNA from New World and more Old World Ascaris samples to tweeze apart the three following hypotheses:

Hypothesis I suggests that mitochondrial differentiation predates the human-pig host switch. This ancestral polymorphism is retained in the descendant species and therefore all three haplotypes should be detectable among all descendant groups, including those infecting pre-Colombian Amerindians that did not domesticate pigs.

Hypothesis II suggests that the human-pig host switch is due to pig domestication and triggered mito- chondrial differentiation. We can also suggest that preColombian Amerindians would have been at least partially immune to the introgressive effects of hybridization between the parasites of pigs and pig farmers in the Old World. Hypotheses I and II both propose that pig domestication coincides with the parasite jumping to a new host and subsequently becoming a new species.

Hypothesis III suggests that the host switch and the mitochondrial differentiation coincided, but both are ancient in origin and neither is the result of pig domestication. The main effect of domestication was to mix up mitochondrial lineages through hybridization.

Thus, hypotheses II and III propose that haplotype differentiation coincides with speciation, but occasional cross-infection and hybridization following the advent of domestication causes interspecific xenology of mitochondria, with A haplotypes jumping into the human parasite and $B$ haplotypes jumping into the pig parasite. Presumably, this hybridization is sufficiently common to contaminate the mitochondrial pattern, but insufficient to disturb the two distinct clusters of nuclear RFLP markers.

Anderson favors hypothesis I because the haplotypes seem too divergent to have coincided with pig domestication, which occurred only 9 to 15,000 years ago. However, without an Ascaris molecular clock, it is hard to evaluate this claim. Even if the haplotypes are ancient, they may well have coincided with a host shift as in hypothesis III, but this would have occurred between early humans and non-domesticated wild boars.

Sequence analysis of nuclear and mitochondrial markers will show whether ancient samples cluster among modern ones, or whether they cluster together closer to the root of the human (or pig) parasite clade, suggesting that even relatively recent time has led to continuing divergence between the genomes of the pig and human parasites.

\section{CONCLUSION}

Paleogenetics may thus be developed as a new efficient tool to parasite evolution studies. DNA sequences from ancient samples should help determine the rhythm of evolution of Ascaris, the migration history of the populations and hopefully the ancestral host. In conclusion, a close collaboration between archaeologists, parasitologists, archaeoparasitolgists, geneticists and paleogeneticists will certainly shed light on the overall history of ascariasis in humans and in pigs.

\section{ACKNOWLEDGEMENTS}

To Dr Klaas Vrieling, Dr William Piel, and Mrs Milka Pejovic-Roller for critical reading of the manuscript and fruitful comments.

\section{REFERENCES}

Anderson TJC 1995. Ascaris infections in humans from North America: molecular evidence for cross-infection. Parasitology 110: 215-219.

Anderson TJC 2001. The dangers of using single locus markers in parasite epidemiology: Ascaris as a case study. Trends Parasitol 17: 183-188.

Anderson TJC, Jaenike J 1997. Host specificity, evolutionary relationships and macrogeographic differentiation among 
Ascaris populations from humans and pigs. Parasitology 115: 325-342.

Anderson TJC, Romero-Abal ME, Jaenike J 1993. Genetic structure and epidemiology of Ascaris populations: patterns of host affiliation in Guatemala. Parasitology 107: 319-334.

Ansel M, Thibaut M 1973. Value of the specific distinction between Ascaris lumbricoides Linné 1758 and Ascaris suum Goeze 1782. Int J Parasitol 3: 317-319.

Araujo A, Ferreira LF 2000. Paleoparasitology and the antiquity of human host-parasite relationships. Mem Inst Oswaldo Cruz 95 (Suppl. I): 89-93.

Blouin MS, Yowell CA, Courtney CH, Dame JB 1998. Substitution bias, rapid saturation, and the use of mtDNA for nematode systematics. Mol Biol Evol 15: 1719-1727.

Bouchet F, Baffier D, Girard M, Morel P, Paicheler JC, David F 1996. Paléoparasitologie en contexte Pléistocène: première observations à la Grande Grotte d'Arcy-sur-Cure (Yonne), France. C R Acad Sci III 319: 147-151.

Bouchet F, West D, Lefevre C, Corbett D 2001. Identification of parasitoses in a child burial from Adak Island (Central Aleutian Islands, Alaska). C R Acad Sci III 324: 123-127.

Buckley JJC 1931. An observation on human resistance to infection with Ascaris from the pig. J Helminthol 9: 45-46.

Chan MS, Medley GF, Jamison D, Bundy DA 1994. The evaluation of potential global morbidity attributable to intestinal nematode infections. Parasitology 109: 373-387.

Crewe W, Smith DH 1971. Human infection with pig Ascaris (A. suum). Ann Trop Med Parasitol 65: 85.

Crompton DW 1999. How much human helminthiasis is there in the world? J Parasitol 85: 397-403.

Crompton DW 2001. Ascaris and ascariasis. Adv Parasitol 48: 285-375.

Denham DA 1984. Ascaris lumbricoides in English schoolchildren. Trans R Soc Trop Med Hyg 78: 566-567.

Dobzhansky T 1937. Genetics and the Origin of Species, Columbia University Press, New York.

Editorial 1989. Ascariasis. Lancet 1 (8645): 997-998.

Epstein H, Mason IL 1984. Evolution of Domesticated Animals, Longman, London and New York, chapter 2, p. 6-27.

Faulkner CT, Patton S, Johnson SS 1989. Prehistoric parasitism in Tennessee: evidence from the analysis of desiccated fecal material collected from Big Bone Cave, Van Buren County, Tennessee. J Parasitol 75: 461-463.

Ferreira LF, Britto C, Cardoso MA, Fernandes O, Reinhard K, Araujo A 2000. Paleoparasitology of Chagas disease revaled by infected tissues from Chilean mummies. Acta Trop 75: 79-84.

Gade DW 2000. The Cambridge World History of Food. In KF Kiple \& KC Ornelas, Cambridge University Press, UK.

Galvin TJ 1968. Development of human and pig Ascaris in the pig and rabbit. J Parasitol 54: 1085-1091.

Geus F 1995. Archaeology and History of Sai Island. The Sudan Archaeological Research Society Newsletter 8: 27-34.

Greenberg JH, Turner II CG, Zegura SL 1986. The settlement of the Americas: a comparison of the linguistic, dental, and genetic evidence. Current Anthropol 27: 477-497.

Guhl F, Jaramillo C, Vallejo GA, Yockteng R, Cardenas-Arroyo F, Fornaciari G, Arriaza B, Aufderheide AC 1999. Isolation of Trypanosoma cruzi DNA in 4,000-year-old mummified human tissue from northern Chile. Am J Phys Anthropol 108: 401-407.

Hagelberg E, Sykes B, Hedges R 1989. Ancient bone DNA amplified. Nature 342: 485.

He L, Min XT, Liu GZ, Xu PB, Li WS 1986. Preliminary karyotype studies on Ascaris lumbricoides and Ascaris suum from Guangzhou [in Chinese]. Chi Sheng Chung Hsueh Yu Chi Sheng Chung Ping Tsa Chih 4: 206-208.
Higuchi RG, Bowman B, Freiberger M, Ryder OA, Wilson AC 1984. DNA sequences from the quagga, an extinct member of the horse family. Nature 312: 282-284.

Horai S, Hayasaka K, Murayama K, Wate N, Koike H, Nakai N 1989. DNA amplification from ancient human skeletal remains and their sequence analysis. Proc Japan Acad serB 65: $229-233$.

Jungersen G 1998. Experimental Ascaris suum infections, Thesis, The Royal Veterinary and Agricultural University, Copenhagen, Denmark.

Jungersen G, Eriksen L, Nansen P, Fagerholm HP 1997. Sexmanipulated Ascaris suum infections in pigs: implications for reproduction. Parasitology 115: 439-442.

Jungersen G, Eriksen L, Nielsen CG, Roepstorff A, Nansen P 1996. Experimental transfer of Ascaris suum from donor pigs to helminth naive pigs. J Parasitol 82: 752-756.

Juniper I 1978. Morphology, diet and parasitism in Quebec black bears. Canadian Field-Naturalist 92: 186-189.

Kliks MM 1983. Paleoparasitology: on the origins and impacts of human-helminth relationships. In NA Croll, JA Cross (eds), Human Ecology and Infectious Diseases, Academic Press, New York, p. 291-309.

Kurimoto H 1974. Morphological, biochemical and immunological studies on Ascaris lumbricoides Linnaeus, 1758 and Ascaris suum Goeze, 1782. Jpn J Parasitol 23: 251-267.

Lord WD, Bullock WL 1982. Swine Ascaris in humans. N Engl JMed 306: 113.

Loreille O, Roumat E, Verneau O, Bouchet F, Hänni C 2001. Ancient DNA from Ascaris: extraction amplification and sequences from eggs collected in coprolites. Int J Parasitol 31: 1101-1106.

Mikulikova L 1976. Studies on species specificity of proteins in Ascaris lumbricoides and Ascaris suum. Folia Parasitol (Praha) 23: 45-50.

Muller WA 1975. Infestation with intestinal helminths in the inhabitants of the city of Dresden. Z Gesamte Inn Med 30: 239-247.

Murrell KD, Eriksen L, Nansen P, Slotved HC, Rasmussen T 1997. Ascaris suum: a revision of its early migratory path and implications for human ascariasis. J Parasitol 83: 255260.

Nadler SA 1987. Biochemical and immunological systematics of some ascaridoid nematodes: genetic divergence between congeners. J Parasitol 73: 811-816.

Nikolic A, Djurkovic-Djakovic O, Bobic B 1998. Intestinal parasitic infections in Serbia. Srp Arh Celok Lek 126: 1-5.

O'Lorcain P, Holland CV 2000. The public health importance of Ascaris lumbricoides. Parasitology 121 (Suppl.): S5171.

Pääbo S 1985. Molecular cloning of ancient Egyptian mummy DNA. Nature 314: 644-645.

Paggi L, Nascetti G, Orecchia P, Mattiucci S, Bullini L 1985. Biochemical taxonomy of ascaridoid nematodes. Parassitologia 27: 105-112.

Patrucco R, Tello R, Bonavia D 1983. Parasitological studies of coprolites of pre-Hispanic Peruvian populations. Curr Anthrop 24: 393-394.

Rausch R, Tiner JD 1948. Studies on the parasitic helminths of the north central states. American Midland Naturalis 39: 728-747.

Reinhard KJ, Hevly RH, Anderson GA 1987. Helminth remains from prehistoric Indian coprolites on the Colorado Plateau. J Parasitol 73: 630-639.

Ruffer MA 1910. Note on the presence of Bilharzia haematobia in Egyptian mummies of the Twentieth Dynasty (12501000 BC). Br Med J 1: 16. 
Sauer CO 1952. Agricultural Origins and Dispersals, American Geographic Society, New York.

Sprent JFA 1952. Anatomical distinction between human and pig strains of Ascaris. Nature 170: 627-628.

Stuart MD, Greenspan LL, Glander KE, Clarke MR 1990. A coprological survey of parasites of wild mantled howling monkeys, Alouatta palliata palliata. J Wildl Dis 26: 547549.
Takata I 1951. Experimental infection of man with Ascaris of man and the pig. Kitasato Arch Exp Med 23: 49-59.

Tomaso H, Dierich MP, Allerberger F 2001. Helminthic infestations in the Tyrol, Austria. Clin Microbiol Infect 7: 639641.

Valentine CC, Hoffner RJ, Henderson SO 2001. Three common presentations of ascariasis infection in an urban Emergency Department. J Emerg Med 20: 135-139. 